\title{
DIFFERENCE OF TUMOR MASS IN STADIUM IIB-IIIB SQUAMOUS CELL CERVICAL CANCER PATIENTS WHO UNDERWENT PACLITAXEL CISPLATIN AND PACLITAXEL CARBOPLATIN CHEMOTHERAPY AT SANGLAH HOSPITAL DENPASAR
}

\author{
RINI NOVIYANI ${ }^{1}$, PUTU AYU INDRAYATHI ${ }^{2}$, I NYOMAN GEDE BUDIANA ${ }^{3}$, KETUT SUWIYOGA ${ }^{3}$, SEPTIARA PUTRI ${ }^{4}$ \\ ${ }^{1}$ Department of Pharmacy, Faculty of Mathematics and Natural Sciences, Udayana University, Postal Code 80361, Bali, Indonesia, \\ ${ }^{2}$ Program Study of Public Health, Faculty of Medicine, Udayana University, Postal Code 80234, Bali, Indonesia, ${ }^{3}$ Department Obstetrics and \\ Gynecology, Faculty of Medicine, University of Udayana, Postal Code 80234, Bali, Indonesia, ${ }^{4}$ Centre for Health Economics and Policy \\ Studies, Faculty of Public Health, University of Indonesia, Postal Code 16424, Jakarta, Indonesia \\ Email: rini.noviyani@gmail.com
}

Received: 15 Jul 2017 Revised and Accepted: 21 Sep 2017

\begin{abstract}
Objective: One of the parameters to measure the efficacy ofthe use of platinum-based chemotherapy was the difference of tumor mass Unfortunately, there was insufficient data about the use of rational chemotherapy medicine for cervical cancer patients at Sanglah Hospital.
\end{abstract} Therefore, research to seek more data about the difference of tumor mass was necessary.

Methods: A prospective observational research was conducted at Sanglah Hospital from January until August 2016 by using consecutive sampling method. Patients qualified for the inclusive criteria were separated into two groups. They were paclitaxel cisplatin group and paclitaxel carboplatingroup. Tumor mass data was obtained from before chemotherapy I and after chemotherapy VI by using USG 2D LOGIQ V5. Data analysed was performed with SPSS 20.0 for windowswith a 95\% confidence level usingWilcoxon test and Mann Whitney test.

Results: The mean values of tumor mass for patients in paclitaxel cisplatin regimen group before chemotherapy I and after chemotherapy VI were $68.91+7.41 \mathrm{~cm}^{3}$ and $10.62+6.82 \mathrm{~cm}^{3}$ respectively( $\mathrm{p}$ value $=0.018$ ). The mean values of tumor mass for patients in paclitaxel carboplatin regimen group before chemotherapy I and after chemotherapy VI were $53.44+52.25 \mathrm{~cm}^{3}$ and $9.18+8.23 \mathrm{~cm}^{3}$ respectively(p value $\left.=0.007\right)$. Meanwhile, the mean values of the difference in tumor mass between both paclitaxel cisplatin and paclitaxel carboplatin groups were-58.29+49.93 $\mathrm{cm}^{3} \mathrm{and}-$ $44.26+51.48 \mathrm{~cm}^{3}$ respectively $(\mathrm{p}$ value $=0.242$ ).

Conclusion: This research showed that there was a significant difference of tumor mass before chemotherapy I and chemotherapy VI in both regimen groups. There was a bigger decrease of tumor mass in patients from paclitaxel cisplatin chemotherapy group compared to paclitaxel carboplatin group, but it was not significantly different.

Keywords: Tumor mass, Cervical cancer, Chemotherapy, Paclitaxel cisplatin, Paclitaxel carboplatin

(C) 2017 The Authors. Published by Innovare Academic Sciences Pvt Ltd. This is an open access article under the CC BY license (http://creativecommons.org/licenses/by/4.0/) DOI: http://dx.doi.org/10.22159/ijpps.2017v9i11.21375

\section{INTRODUCTION}

Cervical cancer is the fourth most common cancer among women and is the seventh most frequently found cancer cases among all the other types of cancer [1]. Cervical cancer is also the most common type of gynecological cancer found at Sanglah Hospital Denpasar in 2015, with the statistics of 200 new cervical cancer cases out of 261 new gynecological cancer casesrecorded. One research shows that $75 \%$ of women with cervical cancer live with limited resources and have cervical cancer with advanced stadium [2]. Cervical cancer is typically managed based on the stadium, with many therapeutic procedures include operation, radiotherapy or the combination of chemotherapy and radiotherapy. The most recommended treatment for cervical cancer patients with advanced stadium is platinumbased chemotherapy. Cisplatin is the most active platinum-based cytotoxic agent [3]. Another platinum-based chemotherapyagent, carboplatin, is less effective compared to cisplatin since the carboplatin dosage has to be four times more than one dosage of cisplatin in order to achieve the same result. However, carboplatin has lower side effects compared to cisplatin,due to its lower nephrotoxic effect when compared to cisplatin [4].

Combined platinum-based chemotherapyis generally selected due to the medicine's resistance and its lower level of toxicity[4]. Combined platinum-based chemotherapy administered at Sanglah Hospital Denpasar is the combination of both paclitaxel cisplatin and paclitaxel carboplatin chemotherapy. Rational method of choosing medicine for chemotherapy is by considering the efficacy of the chemotherapy regimen. Therefore, it is advisable if the combination of paclitaxel cisplatin is compared to alternative chemotherapy regimen for cervical cancer patients so that they will be able to choose the most effective chemotherapy regimen [5]. Combined paclitaxel cisplatin is better than single cisplatin when it is observed from the response rate, progression free survival (PFS), and quality of life (QOL). Combined paclitaxel carboplatin is actively combined chemotherapy for advanced and recurring cervical cancer. This regimen is not only well-accepted but also well-tolerated by patients [6]. Research conducted at Sanglah Hospital Denpasartowards other combined platinum-based chemotherapies for cervical cancer, such as BOM Cisplatin (Bleomycin-vincristine-mitomycin-cisplatin) and BOM Carboplatin (Bleomycin-vincristine-mitomycin-carboplatin) shows that BOM-cisplatin is effective in reducing tumor mass after undergoing chemotherapy. On the contrary, BOM-carboplatin is considered not as effective as the former [7]. Researches that compared the efficacy of combined paclitaxel cisplatin and paclitaxel carboplatin chemotherapy by using tumor mass as the parameter at Sanglah Hospital Denpasar are still limited. Meanwhile, this information is required as a reference in choosing an effective chemotherapy regimen for cervical cancer treatments.

Another factor to be considered while choosing rational chemotherapy is related to the proper frequency of chemotherapy's medicine intake. The intensity of medicine intake will affect the amount of eradicated cancer cells [8]. Based on in vitro research, mathematical model predicts that medicine concentration and the duration of its exposure could increase the number of eradicated cancer cells exponentially [9]. All of these factors are linked to the number of chemotherapy cycles underwent by patients. Paclitaxel cisplatin and paclitaxel carboplatin regimens are generally given for 
the interval of $21 \mathrm{~d}$ with as many as six chemotherapy cycles at Sanglah Hospital [10]. Information about the efficacy of platinum based chemotherapy on cervical cancer patients who underwent six chemotherapy cycles is also insufficient. Thus, in order to provide rational choice of chemotherapy regimen based on the parameter of both the efficacy of chemotherapy regimen and the frequency of chemotherapy medicine intake, a research that compared tumor mass for each chemotherapy regimen on cervical cancer patients before and after chemotherapy I and VI respectively is required. Afterwards, the next step would be to compare the difference of tumor mass between two different chemotherapy regimens, paclitaxel cisplatin and paclitaxel carboplatin, from cervical cancer patients after undergoing six cycles of chemotherapy at Sanglah Hospital.

\section{MATERIALS AND METHODS}

\section{Methods}

This research was conducted prospectively to find out the difference of efficacy from chemotherapies that are using paclitaxel cisplatin and paclitaxel carboplatin regimen when it was observed based on the difference of tumor mass values after undergoing six cycles of chemotherapy on squamous cell cervical cancer stadium IIB-IIIB at Sanglah Hospital. Observation on patients was carried out from January until August 2016 at Sanglah Hospital Denpasar. Consecutive sampling method was used to take samples. This research had been approved by the ethical commission with ethical clearance number 46/UN.14.2/litbang/2016 from Research Ethical Commission Udayana University Medicine Faculty/Sanglah Hospital, Denpasar. The inclusion criteria for patients included new patients with squamous cell cervical cancer stadium IIB-IIIB, patients who filled in informed consent, and gave permission for their medical record like tumor mass be taken, as well as patients who underwent paclitaxel cisplatin or paclitaxel carboplatin chemotherapy and could complete the whole series chemotherapy I until VI. The exclusion criteria for patients included lost to-follow-up patients due to some reasons like death and lost of contact. Tumor mass check was conducted by using USG 2D LOGIQ V5 before chemotherapy I and after chemotherapy VI by the same obstetricians.

After all the data were collected, statistical analysis was conducted with SPSS 20 for Windows with a 95\% confidence level. The data underwent normality test by using Shapiro Wilk test to determine data distribution. Next, data with normal distribution was tested with $\mathrm{t}$ paired test and $\mathrm{t}$ unpaired test. Meanwhile, data with abnormal distribution was tested with Wilcoxon test and Mann Whitney test. Both $\mathrm{t}$ paired test and Wilcoxon test were used to determine the difference of tumor mass before chemotherapy I and after chemotherapy VI in both regimen groups that include paclitaxel cisplatin regimen group and paclitaxel carboplatin regimen group. On the other hand, unpaired t test and Mann Whitney test were also used to determine the difference of tumor mass between the two regimen groups.-Tumor mass data was considered to have meaningful difference if the value of $\mathrm{p}<0.05$.

\section{RESULTS}

\section{Patients' characteristics}

The number of qualified samples acquired during the research that lasted from January until August 2016 was 17 patients. They consisted of 7 patients who underwent paclitaxel cisplatin chemotherapy and 10 patients who underwent paclitaxel carboplatin chemotherapy. Table 1 showed patients' characteristics for each chemotherapy regimen in this research.

Table 1: Squamous cell cervical cancer patients' characteristics with paclitaxel cisplatin and paclitaxel carboplatin chemotherapy

\begin{tabular}{|c|c|c|c|c|c|}
\hline \multicolumn{2}{|c|}{ Patients' characteristics } & \multicolumn{2}{|c|}{ Paclitaxel cisplatin } & \multicolumn{2}{|c|}{ Paclitaxel carboplatin } \\
\hline & & Number $(n=7)$ & Percentage (\%) & Number $(n=10)$ & Percentage (\%) \\
\hline \multirow{2}{*}{ Age (y) } & $36-45$ & 4 & 57.2 & 6 & 60 \\
\hline & $46-65$ & 3 & 42.8 & 4 & 40 \\
\hline \multirow[t]{2}{*}{ Marital status } & Married & 7 & 100 & 10 & 100 \\
\hline & Not married & 0 & 0 & 0 & 0 \\
\hline Marital age & $15-20$ & 4 & 57.1 & 4 & 40 \\
\hline \multirow[t]{2}{*}{ (y) } & $21-26$ & 3 & 42.8 & 4 & 40 \\
\hline & More than 26 & 0 & 0 & 2 & 20 \\
\hline \multirow[t]{2}{*}{ Stadium } & IIB & 0 & 0 & 2 & 20 \\
\hline & IIIB & 7 & 100 & 8 & 80 \\
\hline \multirow[t]{5}{*}{ Living area } & Bali & 3 & 42.9 & 8 & 80 \\
\hline & Lombok & 2 & 28.6 & 1 & 10 \\
\hline & Banyuwangi & 1 & 14.3 & 0 & 0 \\
\hline & Sulawesi & 1 & 14.3 & 0 & 0 \\
\hline & Sumbawa & 0 & 0 & 1 & 10 \\
\hline
\end{tabular}

$\mathrm{n}=$ number of patients

Based on table 1, it could be seen that 10 patients were diagnosed within the age range of 36 until $45 \mathrm{y}$ old,and the other 7 patients were diagnosed within the age range of 46 until $65 \mathrm{y}$ old. All patients in this research were all married, in which 8 of them got married within the age range of 15 until $20 \mathrm{y}$ old, the other 7 patients got married within the age range of $21 \mathrm{until} 26 \mathrm{y}$ old, and the rest 2 patients got married at 26 y old and above. Patients who became the subjects of this research were primarily diagnosed with cervical cancer stadium IIIB (15 patients) and the rest of them were diagnosed with stadium IIB (2 patients). Cervical cancer patients in this research were mainly from Bali, with 11 patients and the rest 6 patients were from outside Bali like Lombok, Banyuwangi, Sulawesi and Sumbawa.

Difference of tumor mass before and after chemotherapy in cervical cancer patients who underwent paclitaxel cisplatin and paclitaxel carboplatin chemotherapy.

Table 2: Data of tumor mass before chemotherapy I and after chemotherapy VI with paclitaxel cisplatin regimen from Wilcoxon test results

\begin{tabular}{lll}
\hline Time of tumor mass measurement & n & Value of tumor mass $\left(\mathbf{c m}^{\mathbf{3}}\right)$ \\
\hline Before chemotherapy 1 & 7 & $68.91+47.41$ \\
After chemotherapy 6 & 7 & $10.62+6.82$ \\
\hline
\end{tabular}

$\mathrm{n}=$ number of patients. *Statistically significant. Data of tumor mass expressed as mean value with plus-minus value as standard deviation. 
Based on table 2, we could see tha the Wilcoxon test results of tumor mass difference before chemotherapy $I$ and after chemotherapy VI with paclitaxel cisplatin regimen was equal to the value of $\mathrm{p}<0.05(\mathrm{p}=0.0180)$.

Table 3: Data of tumor mass before chemotherapy I and after chemotherapy VI with paclitaxel carboplatin chemotherapy from Wilcoxon test results

\begin{tabular}{lll}
\hline Time of tumor mass measurement & n & Value of tumor mass $\left(\mathbf{c m}^{3}\right)$ \\
\hline Before chemotherapy 1 & 10 & $53.44+52.25$ \\
After chemotherapy 6 & 10 & $9.18+8.23$ \\
\hline
\end{tabular}

$\mathrm{n}=$ number of patients. *Statistically significant. Data of tumor mass expressed as mean value with plus-minusvalue as standard deviation.

Table 4: Average data of tumor mass difference in squamous cell cervical cancer patients with paclitaxel cisplatin and paclitaxel carboplatin chemotherapies from Mann Whitney test results

\begin{tabular}{lll}
\hline Chemotherapy regimens & $\mathbf{n}$ & Value of tumor mass $\left(\mathbf{c m}^{3}\right)$ \\
\hline Paclitaxel cisplatin & 7 & $-58.29+49.93$ \\
Paclitaxel carboplatin & 10 & $-44.26+51.48$ \\
\hline
\end{tabular}

$\mathrm{n}=$ number of patients. ${ }^{*}$ Statistically significant. Data of tumor mass expressed as meanvalue with plus-minusvalue as standard deviation.

Based on table 3, we could see that the Wilcoxon test results of tumor mass difference before chemotherapy I and after chemotherapy VI with paclitaxel carboplatin regimen was equal to the value of $\mathrm{p}<0.05(\mathrm{p}=0.007)$.

\section{Difference of tumor mass in cervical cancer patients who underwent paclitaxel cisplatin and paclitaxel carboplatin chemotherapy}

Based on table 4, the Mann Whitney test results showed that there were negative fig. in the mean value column. It showed that there was a decrease in tumor average mass after cervical cancer patients underwent six cycles of chemotherapies. In the group of cervical cancer patients who underwent chemotherapy with paclitaxel cisplatin regimen, the decrease was 58.29+49.93. Meanwhile, in the group of cervical cancer patients who underwent chemotherapy with paclitaxel carboplatin regimen, the decrease was $44.26+51.48$ with the value of $p=0.242(p>0.05)$.

\section{DISCUSSION}

\section{Patients' characteristics}

Based on table 1, it could be seen that 10 patients were diagnosed within the age range of 36 until $45 \mathrm{y}$ old and the remaining 7 patients were diagnosed within the age range of 46 until $65 \mathrm{y}$ old. This is in alignment withresearch that mentioned about how females within the age range of 25-64 y old are the most prevalent ones to be diagnosed with cervical cancer $[11,12]$. All patients in this research were married, in which as many as 8 patients got married within the age range of 15 until $20 \mathrm{y}$ old, 7 patients got married within the age range of 21 until $26 \mathrm{y}$ old, and the remaining 2 patients got married at $26 \mathrm{y}$ old and above. Patients who got married at very young ages indicated that they had their first sexual intercourse at very young ages as well. Having sexual intercourse at very young ages is one of the contributing factors for contracting cervical cancer. Patients who became the subjects of this research were mostly diagnosed with cervical cancer stadium IIIB with 15 patients and the rest of them were diagnosed with stadium IIB with 2 patients. Patients started their treatments during late stadiums since the earlier stadiums of cervical cancer aregenerally without symptoms. The symptoms can become apparent during late stadiums because they include abnormal bleeding vagina or odorous vagina. That's why, this cancer is also known as the silent killer [13]. Cervical cancer patients in this research were mainly from Bali, with 11 patients, and the rest 6 patients were from places outside Bali like Lombok, Banyuwangi, Sulawesi and Sumbawa. Some of the patients from outside Bali were referred to Sanglah Hospital Denpasar to get treatments for cervical cancer. This is attributed to how Sanglah Hospital Denpasar is the referral health facilities for Eastern Indonesia area.

\section{Tumor mass value}

Neoplasm, also known as abnormal tissue, tissue growth or unorganised organ, can commonly form an obvious mass. Neoplasm is the medical term for diseases associated to cancer, tumor, or growth [14]. One of the indicators or one of the effective parameters for chemotherapy that can be observed is tumor mass. If the tumor mass shrinks, it can be inferred that the treatment is effective [15]. Tumor mass plays a role in determining the prognosis for cervical cancer because in some cases, the tumor mass does not correlate or is not compatible with the patients' stadiums [16].

Chemotherapy has the purpose to induce the decrease of tumor mass. The challenge of treatments with anticancer medicine is to avoid relapse that could happen either locally or metastatically from the original tumor's location. One of chemotherapy's classifications based on treatment time is induced chemotherapy. This chemotherapy is initial therapy that has the purpose to achieve the decrease of significant tumor cell numbers and can ideally eradicate the disease completely [17].

In this research, tumor mass was used as an indicator to evaluate the success of both paclitaxel cisplatin and paclitaxel carboplatin chemotherapy in squamous cell cervical cancer case. Tumor mass check was conducted before chemotherapy cycle I and after chemotherapy cycle VI with USG 2D LOGIQ V5 by the same doctor for every cervical cancer patient that becomes the research subject, for both paclitaxel cisplatin and paclitaxel carboplatin chemotherapies' patients. From this research, data with abnormal distribution was found in two regimen groups with Wilcoxon test. The result showed that paclitaxel cisplatin and paclitaxel carboplatin chemotherapy regimens can achieve the target of chemotherapy which is to reduce the number of tumor cells significantly.

Wilcoxon test result in table 2 showed that there was a difference of tumor mass before chemotherapy I and after chemotherapy VI with paclitaxel cisplatin regimen and the acquired value of $p=0.018$. The $\mathrm{p}$ value was less than 0.05 which shows there was a significant difference of tumor mass after patients had undergone six cycles of chemotherapy with paclitaxel cisplatin regimen. This shows how paclitaxel cisplatin regimen is an effective chemotherapy regimen for decreasing tumor mass. Research by Monk et al.,(2009) showed that patients who underwent paclitaxel cisplatin chemotherapy had the highest response rate compared to vinorelbin cisplatin, gemcitabine cisplatin or even topotectan cisplatin with the result of $29.1 \%$ [18]. Research by Mooreet al.(2004) showed the response rate as much as $36 \%$ on patients who underwent paclitaxel cisplatin chemotherapies, where the response rate of paclitaxel cisplatin was higher compared to single cisplatin [5].

Wilcoxon test result in table 3 showed there was a difference of tumor mass before chemotherapy I and after chemotherapy VI with paclitaxel carboplatin regimen and the acquired value of $\mathrm{p}=0.007$. The $\mathrm{p}$ value was less than 0.05 which shows there was a significant difference of tumor mass after patients had undergone six cycles of chemotherapy with paclitaxel carboplatin regimen. This shows how 
paclitaxel carboplatin regimen is also an effective regimen for decreasing tumor mass on cervical cancer patients. Retrospective research by Garces et al., (2013) showed that paclitaxel carboplatin is active regimen and well-tolerated by advanced stadium cervical cancer patients. Recorded objective responses were $34.6 \%(5.2 \%$ from complete response and $29.4 \%$ from partial response) [19].

In this research, it could also be seen that the measured tumor mass after 6 cycles of chemotherapy with paclitaxel cisplatin regimen was $10.62+6.82 \mathrm{~cm}^{3}$ and the tumor mass after 6 cycles of chemotherapy with paclitaxel carboplatin was $9.18+8.23 \mathrm{~cm}^{3}$. This showed that both paclitaxel cisplatin and paclitaxel carboplatin chemotherapy regimens for six cycles were not able to eradicate a tumor mass completely. Thus, these chemotherapies were often used as a part of multiversity therapy that was combined with other therapies such as surgeries and/or radiotherapies to achieve and maintain the decrease of tumor mass [17]. This statement was supported by research conducted by Mandic (2005) that concluded around 44\% cervical cancer patients who underwent combined chemoradiotherapy experienced from a decrease of tumor mass for as much as 50\% [14]. Research by Tan and Zahra (2008) also showed that the addition of chemotherapy along with radiotherapy for cervical cancer patients could extend patients' life expectancy aside of toxicity reaction experienced by them[20]. Therefore, further research to learn more out about the efficacy of cervical cancer treatment that includes both chemotherapy and radiotherapy is necessary.

This research observed the tumor mass before and after patients underwent 6 series of chemotherapy. It showed a significant decrease after patients underwent 6 series of chemotherapy, for either paclitaxel cisplatin regimen or paclitaxel carboplatin regimen. Previous researches also demonstrated a significant difference of tumor mass after three cycles of paclitaxel carboplatin chemotherapy on squamous cell cervical cancer patients [21]. Research on advanced stadium non-small-cell lung cancer patients showed that six cycles of platinum-based chemotherapy were not able to increase the overall survival compared to 3 or 4 cycles [22]. Research by Angioli (2015) showed that adjuvant chemotherapy with 4 and 6 cycles showed similar outcomes towards the overall survival and disease free survival [23]. More specific researches about tumor mass decrease with 6 cycles of chemotherapy and lower cycles have to be compared in order to determine the optimum cycle for chemotherapy with paclitaxel cisplatin and paclitaxel carboplatin regimens.

Paclitaxel cisplatin and paclitaxel carboplatin regimens are the combination of cytostatic taxane and platinum class. Combined chemotherapy has the aim to kill tumor cells maximumly with a distinctive method and work at different parts of a cell cycle [17]. Paclitaxel is associated with potent microtubule activity while increasing microtubule formation and preventing depolymerisation. This leads to mitosis resistance and apoptosis induction during cell division. This happens during specific cell cycle which is the Mphase. Cisplatin and Carboplatin will bind covalently with DNA to form crossed bind and interstrand DNA that lead to DNA's damage during replication. It will hamper transcription, synthesis and DNA function [8]. The two groups of combined chemotherapy regimens come from taxane and platinum class so both of them have similar cell killing mechanism and have comparablepotential efficacy as well. This research also employed data analysis with Mann Whitney test that compared the decrease of tumor mass of both regimens. Results of Mann Whitney test in table 4 showed that paclitaxel cisplatin regimen experienced a decrease of $58.29+49.93$. On the other hand, the group of cervical cancer patients who underwent paclitaxel carboplatin chemotherapy experienced a decrease of $44.26+51.48$. The obtained $p$ value was $0.242(p>0.05)$. This showed that there was no significant differences towards the decrease of tumor mass between these two regimens. However, the decrease of tumor mass took place more significantly on cervical cancer patients who underwent paclitaxel cisplatin chemotherapy.

Research by Kitagawa et al. (2015) that compared the efficacy of paclitaxel cisplatin chemotherapy with paclitaxel carboplatin on both metastatic and recurring cervical cancer patients showed a response rate (percentages of patients who achieved complete and partial responses) of $58.8 \%$ for patients with paclitaxel cisplatin regimen and $62.2 \%$ for patients with paclitaxel carboplatin chemotherapy ( $\mathrm{p}=0.665$ ) [24]. Retrospective research by Moore $e t$ al., (2007) showed there was no difference statistically towards response rate between patients who underwent paclitaxel cisplatin and paclitaxel carboplatin chemotherapy. But, the response rate of paclitaxel carboplatin was better compared to paclitaxel cisplatin with $53.3 \%$ and $28.8 \%$ respectively. Better practicality along with toxicity profile for paclitaxel carboplatin has made this regimen worthy to be considered for further cervical cancer treatment, either recurring or progressive [25].

The obtained results from this research are in accordance with other researches that showed no significant difference towards efficacy's parameters that include tumor mass and response rate between these two regimens. Nevertheless, there was a difference between this research with the other researches in terms of how this research managed to show bigger decrease of tumor mass for paclitaxel cisplatin regimen. On the contrary, other researches showed a higher response rate for paclitaxel carboplatin regimen. This might be the result of the inadequate number of samples included in this research that leads to how the result was still not representative enough. Therefore, additional research with a bigger number of samples is necessary. Research about toxicity profile from the use of these two regimens is also necessary as a parameter in choosing the suitable regimen for cervical cancer patients.

\section{CONCLUSION}

Paclitaxel cisplatin and paclitaxel carboplatin chemotherapy show significant differences towards tumor mass before chemotherapy I and after chemotherapy VI with each regimen show the value of $p=0.0180$ and $p=0.007$ respectively. Paclitaxel cisplatin show bigger decrease in tumor mass compared to paclitaxel carboplatin $\left(58.29+49.93 \mathrm{~cm}^{3}\right.$ vs $\left.44.26+51.48 \mathrm{~cm}^{3}\right)$. However, these two regimens do not show significant difference statistically $(\mathrm{p}=0.242)$.

\section{Limitations}

This study was carried out with a limited number of patients who could finish six cycles of chemotherapy at Sanglah Hospital, Denpasar. This study only covered patients in Sanglah Hospital, Denpasar, for a limited period of time and therefore cannot be extrapolated to other regions in Indonesia. To arrive at an evidence-based conclusion, multicentre studies with a larger population are required.

\section{ACKNOWLEDGEMENT}

The authors would like to thank the Ministry of Research, Technology, and Higher Education of the Republic of Indonesia along with all of the obstetrics staffs at Sanglah Hospital Denpasar for their assistance and cooperation.

\section{AUTHOR CONTRIBUTION}

As the Principal Investigator, Rini Noviyani had the responsibility to design the study, develop the methodology, collect data, monitor data collection, write statistical analysis plan, analyze the data, interpret data, draft and revise the paper. Putu Ayu Indrayathi had the responsibility to do data collection, monitor data, draft and revise the paper. Both I Nyoman Gede Budiana and Ketut Suwiyoga had the responsibilities to develop the methodology and collect data. Septiara Putri had the responsibility to design statistical analysis plan and analyze the data.

\section{CONFLICT OF INTERESTS}

Authors declare no conflict of interset

\section{REFERENCES}

1. GLOBOCAN. Cervical cancer estimated incidence, mortality and prevalence worldwide in 2012. France: International Agency for Research on Cancer (IARC); 2012.

2. Elit LM, Hirte H. Management of advanced or recurrent cervical cancer: chemotherapy and beyond. Expert Rev Anticancer Ther 2014;14:319-32.

3. Colombo N, Carinelli S, Colombo A, Marini C, Rollo D, Sessa C. Cervical cancer: ESMO Clinical Practice Guidelines for diagnosis, treatment and follow-up. Ann Oncol 2012;23 Suppl 7:vii27-32. 
4. Dasari S, Tchounwou PB. Cisplatin in cancer therapy: molecular mechanisms of action. Eur J Pharmacol 2014;740:364-78.

5. Moore DH, Blessing JA, McQuellon RP, Thaler HT, Cella D, Benda J, et al. Phase III study of cisplatin with or without paclitaxel in stage IVB, recurrent, or persistent squamous cell carcinoma of the cervix: a gynecologic oncology group study. J Clin Oncol 2004;22:3113-9.

6. Tinker AV, Bhagat K, Swenerton KD, Hoskins PJ. Carboplatin dan paclitaxel for advanced and recurrent cervical carcinoma: the brithis columbia cancer agency experience. J Gynecol Oncol 2005;98:54-8.

7. Noviyani R, Suwiyoga K, Budiana ING, Tunas K, Indrayathi PA Effectiveness and toxicity differences between the use of regimen-chemotherapy bleomycin-vincristine-mitomycincisplatin and bleomycin-vincristine-mitomycin-carboplatin for three cycles in patients cervical cancersquamous cell stadium IIB-IIIB in sanglah general hospital denpasar bali. Asian J Pharm Clin Res 2016;9 Suppl 2:149-53.

8. Perry MC. The chemotherapy source book. Colombia: Lippincott William and Wilkins; 2008.

9. Furie B, Cassileth PA, Atkins MB, Mayer RJ. Clinical hematology and oncology presentation, diagnosis and treatment. United States: Churchill Livingston and Imprint of Elsevier; 2003.

10. Komite Medik. Prosedur tetap kemoterapi kanker serviks. Denpasar: Rumah Sakit Umum Pusat Sanglah; 2011.

11. WHO (World Health Organization). Comprehensive cervical cancer control a guide to essential practice. Switzerland: World Health Organization; 2014.

12. Alves C, Alves L, Lunet N. Epidemiology of cervical cancer. Arquivos De Midicina 2010;24:266-77.

13. Pandey D, Shetty J, Sambhaji C, Saxena PU, Mishra D, Chawla A. Cervical cancer as a silent killer: a rare case report. J Can Res Ther 2015;11:653.

14. Mandic A. Neoadjuvant chemotherapy in treatment of cervical cancer-controversies. Arch Oncol 2005;13:89-90.

15. Aziz F, Andrijono, Saifuddin AB. Buku acuan nasional onkologi ginekologi. Jakarta: Yayasan Bina Pustaka Sarwono Prawirohardjo; 2006. p. 359-442.

16. Miller T, Perry G. Measurement of tumor volume by PET to evaluate prognosis in patients with advanced cervical cancer treated by radiation therapy. Int J Radiat Oncol Biol Phys 2002;53:353-9.

17. Airley R. Chemotherapy cancer basic science to the clinic. Great Britain: John Wiley and Sons Ltd; 2009. p. 55-8.

18. Monk BJ, Sill MW, McMeekin DS, Cohn DE, Ramondetta LM Boardman $\mathrm{CH}$, et al. Phase III trial of four cisplatin-containing doublet combinations in stage IVB, recurrent, or persistent cervical carcinoma: a gynecologic oncology group study. J Clin Oncol 2009;27:4649-55.

19. Garces AHI, Mora PAR, Alves FPG, Carmo CC, Grazziotin R, Fernandes ACFM, et al. First-line paclitaxel and carboplatin inpersistent/recurrent or advanced cervical cancer a retrospective analysis of patients treated at Brazilian National Cancer Institute. Int J Gynecol Cancer 2013;23:743-8.

20. Tan LT, Zahra M. Long-term survival and late toxicity after chemoradiotherapy for cervical cancer $d$ the addenbrooke's experience. Clin Oncol 2008;20:358-64.

21. Noviyani R, Suwiyoga K, LesmanaI, Niruri R, Tunas K, Budiana ING. Differences of tumor masses and hemoglobin levels incervical cancer squamous cell type patients treatedwith combination of paclitaxel and carboplatinchemotherapy. $\mathrm{Br}$ Med J 2014;3:15-7.

22. Rossi A, Chiodini P, Sun JM, O'Brien MER, Plessen CV, Barata F, et al. Six versus fewer planned cycles of first-line platinumbasedchemotherapy for non-small-cell lung cancer: a systematicreview and meta-analysis of individual patient data. Lancet Oncol 2014;15:1254-62.

23. Angioli R, Plotti F, Aloisi A, Scaletta G, Capriglione S, Luvero D, et al. A randomized controlled trial comparing four versussix courses of adjuvant platinum-based chemotherapy inlocally advanced cervical cancer patients previouslytreated with neo-adjuvant chemotherapy plus radicalsurgery. Gynecol Oncol 2015;199:433-8.

24. Kitagawa R, Katsumata N, Shibata T, Kamura T, Kasamatsu T, Nakanishi T, et al. Paclitaxel plus carboplatin versus paclitaxel plus cisplatin in metastatic or recurrent cervical cancer: the open-label randomized phase III trial JCOG0505. J Clin Oncol 2015;33:1-7.

25. Moore NK, Herzog TJ, Lewin S, Giuntoli RL, Armstrong DK, Rocconi RP, et al. A comparison of cisplatin/paclitaxel and carboplatin/paclitaxel in stage IVB, recurrent or persistent cervical cancer. Gynecol Oncol 2007;105:299-303. 